\title{
Mezzo-scopic Analysis of Fracture Toughness in Steels
}

\author{
Takashi Miyata*, Tetsuya Tagawa \\ Dept. of Materials Science \& Engineering, Nagoya University, Nagoya 464-8603, Japan
}

Received: August 28, 2001; Revised: December 29, 2001

\begin{abstract}
The cleavage fracture toughness of steels was mezzo-scopically analyzed on the basis of the statistical local fracture criterion approach. The statistical stress criterion at the crack tip region suggests that the cleavage fracture toughness in steels can be described as a function of the yield stress, the cleavage fracture stress, and other mechanical properties of the materials. Formulation of the cleavage fracture toughness was first examined through an investigation on correlation between the cleavage toughness and the cleavage fracture stress obtained in notched round bar specimens in accordance with the theoretical prediction. Then, the scatter of the toughness, specimen thickness effect on the toughness, deterioration of the toughness due to cold working and irradiation, and improvement of the toughness caused by the $\mathrm{Ni}$ addition, were analyzed through the formulation of the toughness.
\end{abstract}

Keywords: cleavage fracture toughness, local criterion approach, weibull stress, formulation of toughness, thickness effect, deterioration of toughness, steels

\section{Introduction}

It is generally accepted that the transgranular cleavage fracture of steels in the transition temperature range is governed by the propagation of micro-crack nucleated at carbide particles, non-metallic inclusions and martensitic islan$\mathrm{ds}^{1-4}$. McMahon and Cohen ${ }^{1}$ had first demonstrated that the cracking of carbide particles at ferrite grain boundaries represents a primary cleavage fracture mechanism in steels. Many authors demonstrated up to the present that brittle cleavage fracture in steels initiates at some particles that are more harder and brittle than the surrounding ferrite matrix ${ }^{2-8}$. The cleavage fracture is promoted by factors that produce locally elevated tensile stress, since tensile stress governs the propagation of a micro-crack as a Griffith $\operatorname{crack}^{2,5-7}$. The cleavage crack once initiated can propagate with low energy dispersion and results unstable propagation. It implies that the fracture obeys the Weakest Link Analogy and statistical distribution of the critical fracture stress shows the Weibull distribution. Formulation of the Weibull stress criterion to describe the cleavage fracture of steels was first performed by Beremin ${ }^{9}$ and Mudry ${ }^{10}$.

Incorporation of local criteria to analytical or numerical solutions for stress distribution at the crack tip derives an expression of fracture toughness in terms of flow and fracture properties of materials as is representatively shown in RKR mode ${ }^{11}$. Statistical modeling for fracture proposed by Beremin gives more rational expression of the cleavage frac-

*e-mail: abe@numse.nagoya-u.ac.jp

Trabalho apresentado no IV Coloquio Latinoamericano de Fractura y Fatiga ture toughness because the physical nature of the cleavage fracture is explicitly taken into account.

The cleavage fracture toughness of steels is quite sensitive to metallurgical factors, and it strongly depends on temperature, strain rate and constraint due to variation in the specimen thickness, in the notch depth and in the scale of yielding at the crack tip ${ }^{12,13}$. Degradation in the toughness due to pre-straining, irradiation and strain aging, or so on, has been often reported. However, the factors that deteriorate the toughness have been individually, experimentally discussed till the moment. The dislocation theory and other microscopic approach may significantly contribute for analysis on the fracture and toughness of steels, while they give little quantitative information on mechanical factors responsible to the toughness. On the other hand, the mezzoscopic description or formulation of the toughness can be expected to give more comprehensive, more quantitative understanding of all subjects responsible to the toughness, and it may lead to the development of improvement of the toughness.

Statistical model ${ }^{9}$ was successfully applied to analyze scatter of toughness ${ }^{14}$, increase of the toughness caused by the loss of constraint due to shallow notch ${ }^{15}$, and applied for qualification of the toughness ${ }^{16}$. In the present work, simplification of the statistical model is first performed to describe the cleavage toughness of various type of steels involving a mild steel and a low alloy steel. Theoretical de- 
scription of the toughness is experimentally confirmed through a correlation between the cleavage fracture toughness obtained in toughness test and the yield/cleavage fracture strength obtained in round bar tensile test. Then, the effects of various mechanical and metallurgical factors on the toughness are discussed on the basis of the comprehensive formulation of the toughness. The experimental results including those reported already elsewhere are analyzed.

\section{Statistical Local Fracture Criterion and Description of Fracture Toughness}

According to the 2 parameter Weibull statistics, probability of failure for a certain volume of material, $V$ subjected to gradient tensile stress $\sigma_{\mathrm{i}}$ is assumed to be

$$
P=1-\exp \left[-\int_{V}\left(\frac{\sigma_{i}}{\sigma_{0}}\right)^{m} \frac{d V}{V_{0}}\right\rfloor=1-\exp \left[\left(\frac{\sigma_{w}}{\sigma_{0}}\right)^{m}\right\rceil
$$

where, $V_{o}$ is the statistical unit volume, $m$ and $\sigma_{\mathrm{o}}$ are the shape parameter and the scale parameter of the Weibull cleavage fracture stress, respectively ${ }^{9}$. The Weibull stress is denoted as $\sigma_{\omega}$. Equation (1) can be applied to the fracture toughness specimen. With the assumption that the stress singularity at the crack tip is given in terms of normalized coordinate $\left(r / J, r / K^{2}\right)$ such as the HRR solution, the integral term in Eq. (1) is deduced to

$$
\int_{V} \frac{\sigma_{i}^{m}}{V_{0}} d V=\sigma_{w}^{m}=B\left(\frac{K}{\sigma_{y s}}\right)^{4} \sigma_{y s}{ }^{m} F\left(n, m, V_{0}\right)
$$

where $B$ is the specimen thickness, $\sigma_{\mathrm{ys}}$ is the yield strength, $n$ is the strain hardening exponent of materials and $F$ is a function of $m, n$ and $V_{o}$. Equation (2) indicates that the fracture toughness shows statistically the Weibull distribution with the constant shape parameter of 4 when the toughness is expressed in the stress intensity factor ${ }^{9,14,17}$. For a certain failure probability, the $\mathrm{K}_{\mathrm{c}}$ value is given by

$$
\mathrm{K}_{\mathrm{c}}=\frac{C\left(n, m, V_{0}\right)}{B^{1 / 4}} \sigma_{y s}\left(\frac{\sigma_{0}}{\sigma_{y s}}\right)^{m / 4}
$$

where $C\left(m, n, V_{o}\right)$ is a function of $n, m$ and $V_{o}$. Equation (3) gives a theoretical foundation for a correlation between the fracture toughness and other mechanical properties of materials. Simultaneously, Equation (3) also indicates that the variation of the toughness with temperature, strain rate, and others may be primarily governed by the variation of the yield stress of the materials since the cleavage fracture stress can be assumed to be independent of those factors ${ }^{18-21}$.

Validity of the statistical Beremin model expressed as Eq. (3) has been confirmed for the temperature dependence ${ }^{17}$ and the scatter of the toughness ${ }^{18}$. Instead of the Weibull cleavage fracture stress, the fracture stress defined in deterministic terms has been adopted in the present work to confirm the description of the fracture toughness by the local criterion approach, because it needs a great number of specimens to obtain the statistical Weibull parameters.

In order to investigate the correlation between the fracture toughness and the cleavage fracture stress, more than 50 types low carbon structural steels including from a mild steel to a low alloy high strength steel with a yield strength of $250 \mathrm{MPa}$ to $1,100 \mathrm{MPa}$, are tested. Cleavage fracture stress, $\sigma_{c}$ is defined as the local maximum principle stress at the cleavage fracture initiation in round bar tensile specimens with $1 \mathrm{~mm}$ radius circumferential notch as shown in Fig.1. Tensile tests were performed at the liquid nitrogen temperature and the critical stresses were calculated by the axisymmetric finite element analysis using the constitutive equation for each material. For several materials the Weibull fracture stress was also obtained from repeated tests under the same condition.

Figure 2 shows the correlation between the scale parameter of the critical Weibull stress, $\sigma_{\mathrm{o}}$ and the critical fracture stress, $\sigma_{c}$ for 13 to 20 specimens of seven types ferrite/ pearlite steels with different grain size ${ }^{22}$. Although the Weakest link analogy stimulates the size and geometry dependence of the deterministic critical fracture stress, good correlation between $\sigma_{o}$ and $\sigma_{c}$ can be observed. This result indicates the deterministic critical fracture stress can be representative to the statistical Weibull fracture stress. Accord-

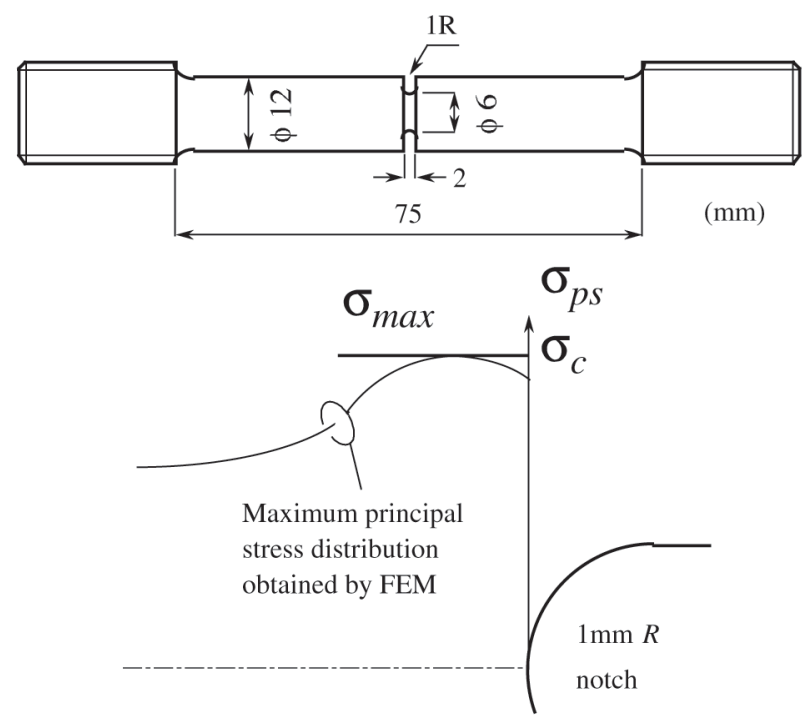

Figure 1. Configuration of notched round bar specimen and definition of the cleavage fracture stress $\sigma_{c}$. 
ing to the analogy of the statistical model, fracture toughness can be expected to be,

$$
K_{c}\left(J_{c}\right)=\frac{C m}{B^{1 / 4}} \sigma_{c}\left(\frac{\sigma_{c}}{\sigma_{y s}}\right)^{\alpha}=
$$

Formulation of the toughness such as in Eq. (4) had been experimentally suggested by Hahn et $a .^{23}$.

Toughness tests at various temperature were carried out for the CT specimens and the three point bend specimens. The cleavage fracture toughness were evaluated in J-integral and converted to the equivalent $\mathrm{K}_{\mathrm{c}}$ values denoted as $K_{c}\left(J_{c}\right)$. Testing was performed in accordance with the ASTM E1820 except for the specimen size prescription. For the correlation with the critical stress, all toughness data were utilized that satisfy the condition of

$$
B, b \geq 10\left(\frac{J_{c}}{\sigma_{y s}}\right)
$$

where $b$ is the pre-crack length of the toughness specimens. Equation (5) seems to be lenient to obtain the valid toughness for constraint effect. However, in-plane constraint effect can be assumed to be not so large ${ }^{13}$ insofar as the fracture toughness is discussed in the sense of accuracy in the following discussion. Specimen thickness effect was taken into account and converted to the equivalent value for $25 \mathrm{~mm}$ thickness from the following relation that is obtained from Eq. (4).

$K_{c}^{4} B=$ constant $K_{c}^{4} B=$ constant

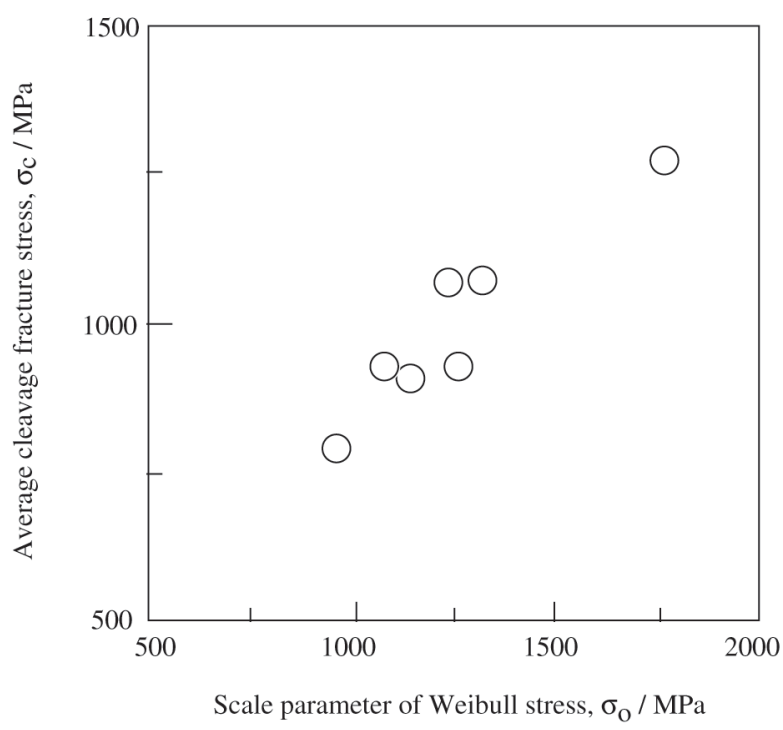

Figure 2. Relation between $\sigma_{c}$ and $\sigma_{\mathrm{o}}$ for ferrite/pearlite steels with different grain size ${ }^{22}$.
Figure 3 shows correlation according to Eq. (4) between the fracture toughness and the cleavage fracture stress obtained in the notched round bar tensile tests. The value of $C_{m}$ and $\alpha$ are materials constants, respectively, determined from the least square method to give the most high correlation coefficient for each material. Notations of $M, B_{U}, B_{L}, F \& P$ indicate micro-structure of materials, that is, martensite, upper bainite, lower bainite, and ferrite/pearlite, respectively. $\mathbf{M}^{*}$ indicates the martensitic islands. Good correlation can be observed and the validity of formulation as Eq. (4) has been confirmed. The value of the materials constant $C_{m}$ can be assumed theoretically and experimentally to be not so sensitive to the material. Assuming a constant value of $C_{m}$ irrespective of the materials, a correlation was again investigated as shown in Fig. 4. Almost similar correlation as in Fig. 3 can be obtained and is expressed for the mean value as

$$
K_{c}\left(\mathrm{MPam}^{1 / 2}\right)=\frac{2.85 \times 10^{-3}}{B(\mathrm{~mm})^{1 / 4}} \sigma_{y s}(\mathrm{MPa})\left(\frac{\sigma_{c}}{\sigma_{y s}}\right)^{\alpha}
$$

Examples of the temperature dependence of the fracture toughness are shown in Fig. 5 and solid lines indicate predicted values from the notched round bar specimens according to Eq. (7). The value of exponent $\alpha$ may be related to the statistical characteristics of micro-crack nuclei as is presumed from the Beremin Model ${ }^{9}$. Figure 6 shows the values of $\alpha$ for each material in relation with the transition temperature of the fracture toughness at which the toughness takes the value of $150 \mathrm{MPam}^{1 / 2}$. The values of $\alpha$ are in the range from 3.5 to 5.0 , and show general tendency that

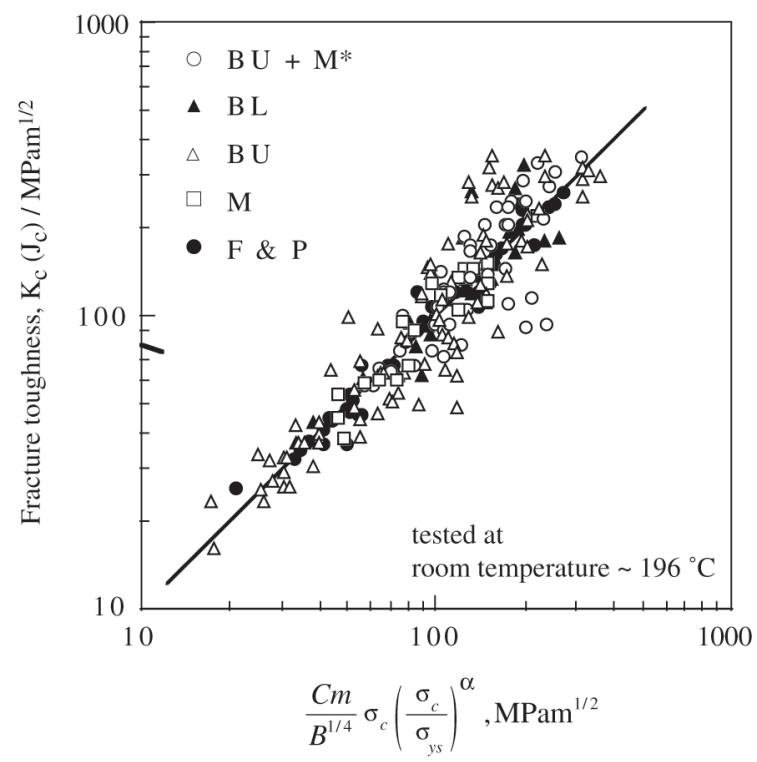

Figure 3. Relation between fracture toughness and cleavage fracture/yield stress in accordance with Eq. (4). 


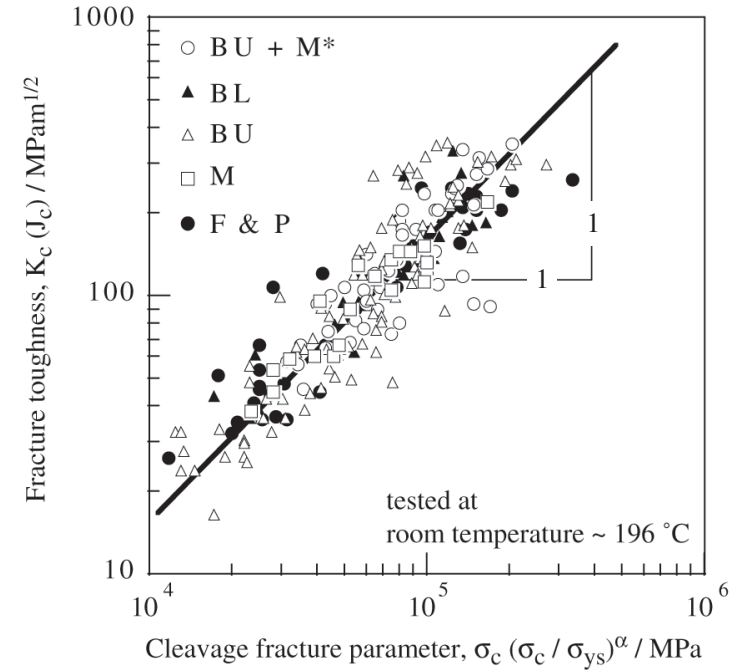

Figure 4. Relation between fracture toughness and cleavage fracture parameter obtained by round bar specimens in accordance with Eq. (7).

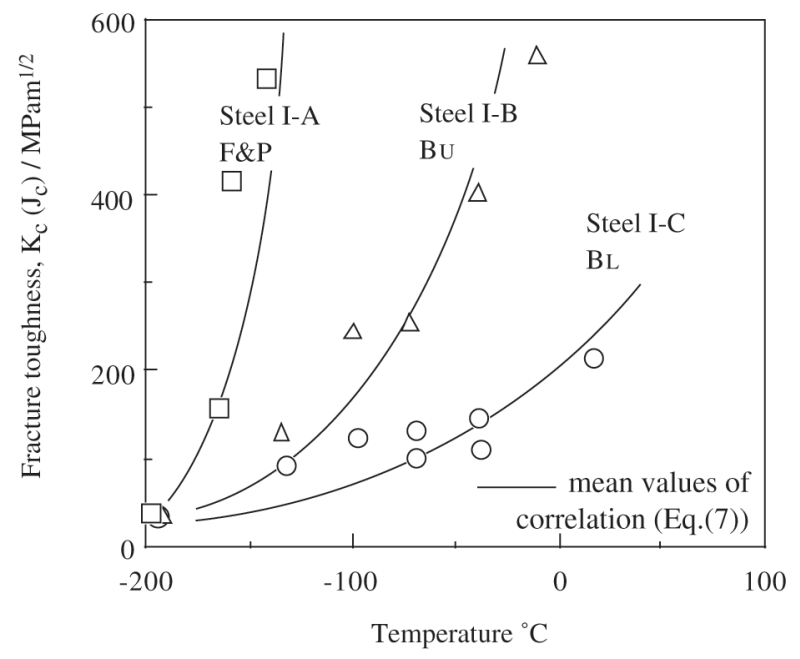

Figure 5. Temperature dependence of fracture toughness for low carbon steels.

the materials with inferior toughness and higher transition temperature have low values of $\alpha$.

\section{Influential Factors on the Fracture Toughness and its Analysis}

According to the formulation expressed in Eq. (7), the influence of various factors on the fracture toughness can be quantitatively presumed. Several factors that have an influence on the toughness shall be discussed.

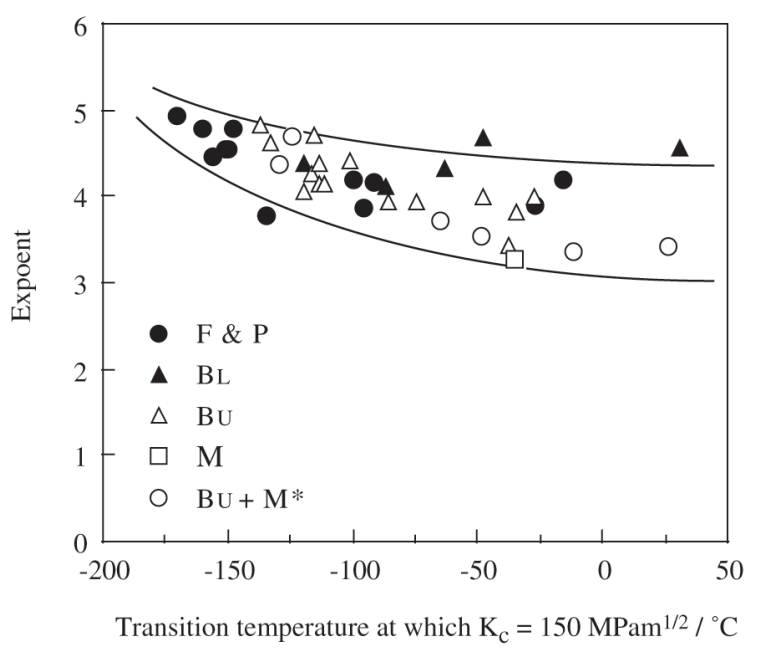

Figure 6. Variation in espoent $\alpha$ with transition temperature for all steels tested.

\section{Thickness effect on the fracture toughness}

The size effect on the cleavage fracture toughness for a fine grained $\mathrm{Ni}-\mathrm{Cr}-\mathrm{Mo}-\mathrm{V}$ steel had been rigorously investigated by the JSPS Committee $129^{24}$. The mean values of the toughness for a lot of specimens are shown in Fig. 7 in relation to the specimen thickness. All other dimensions of the toughness specimens are proportional to the thickness. Predicted value from Eq. (6) is also shown as a fine solid line. Although the stress state in the thickness direction is varied from the plain strain in the mid-thickness region to the plane stress in the specimen surface, volume effect strictly in accordance with Eq. (6) can be observed. The statistical local approach on the basis of the two parameters Weibull statistics does not give a lower saturation in the size effect. The values of $K_{c}$ obtained by specimens which satisfy the plane strain condition given in the ASTM Standard, might be regarded as the plane strain fracture toughness, $\mathrm{K}_{\mathrm{Ic}}{ }^{25}$ as is given in Fig. 7 .

\section{Scatter of the fracture toughness}

As is presumed from Eq. (2), statistical local fracture criterion approach suggests that the statistical distribution of the cleavage fracture toughness of steels is expected to be the Weibull distribution with a constant shape parameter of 4 . Figure 8 shows the Weibull plots of the fracture toughness of a fine and a coarse grained $\mathrm{Ni}-\mathrm{Cr}-\mathrm{Mo}-\mathrm{V}$ steel, a mild steel (SM41B), and a high strength steel embrittled with martensitic islands (Steel A). The Weibull shape parameter, $\beta$ are given in the figure. It should be noticed that the values of shape parameter are not so varied with materi- 


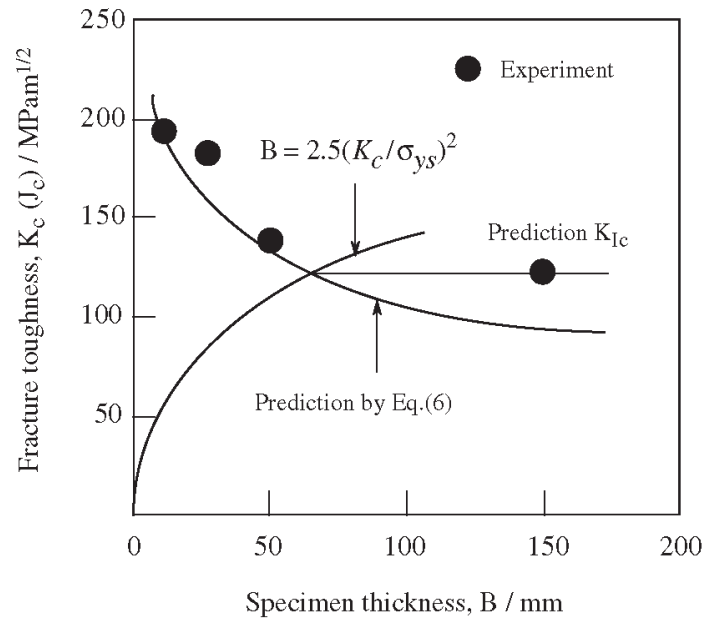

Figure 7. Effect of specimen size on fracture toughness ${ }^{24}$ (finegrained $\mathrm{Ni}-\mathrm{Cr}-\mathrm{Mo}-\mathrm{V}$ steel, $-20{ }^{\circ} \mathrm{C}$ ).

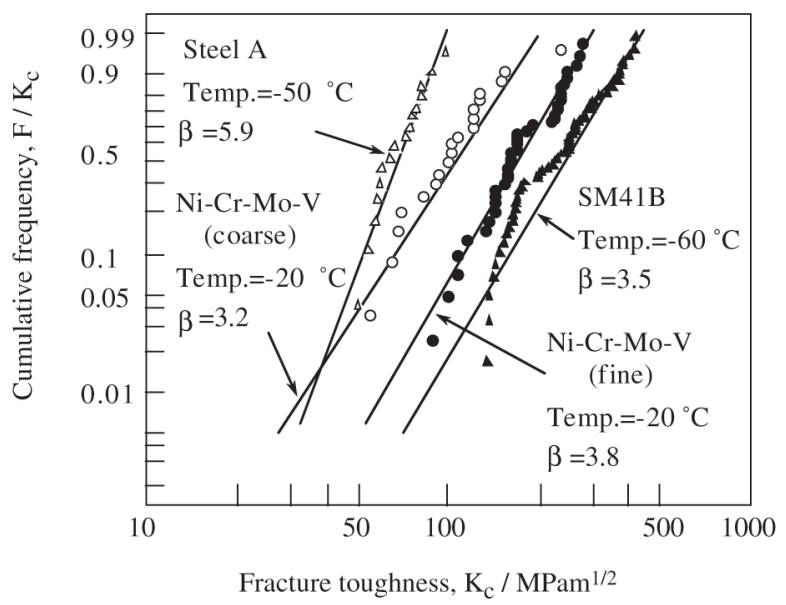

Figure 8. Weibull distributions of fracture toughness.

als. The shape parameters are shown in Fig. 9 as a function of number of specimens tested, together with other experimental data ${ }^{24}$. The solid lines in the figure show results of the Monte-Calro simulation with an assumption of constant shape parameter of 4 . Although the experimental results involve several data set with a little amount of ductile crack growth preceding the cleavage fracture, the experimental results are well consistent with the theoretical prediction in Eq. (2).

\section{Deterioration of the toughness due to pre-straining}

Pre-straining or cold working deteriorates the cleavage fracture toughness of steels, and degree of deterioration

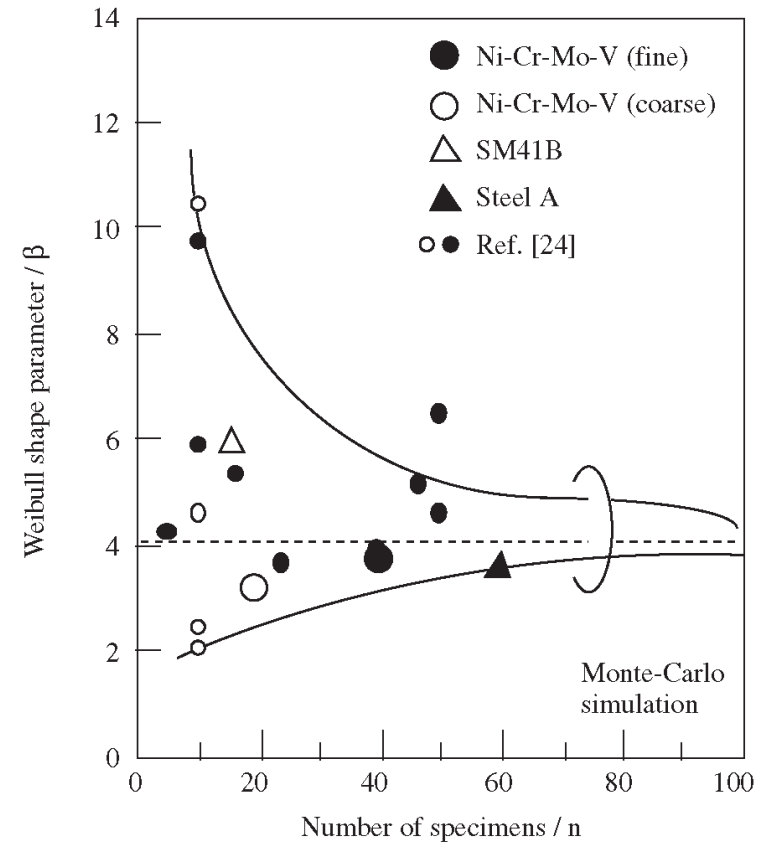

Figure 9. Weibull shape parameter for fracture toughness and number of specimen.

seems to be dependent on materials ${ }^{26,27}$. Small amount of pre-straining doesn't have any influences on the cleavage fracture stress as is shown in Fig. 1022. Figure 10 shows experimental results on the effect of pre-strain on the yield stress and the cleavage fracture stress of two low carbon steels. Provided that the cleavage fracture stress, $\sigma_{c}$ and exponent $\alpha$ in Eq. (7) are not varied with the pre-straining, the deterioration in the toughness is approximately obtained from

$$
\frac{K_{c} \text { pre }- \text { strain }}{K_{c} \text { virgin }}=\left(\frac{\sigma_{y s} \text { virgin }}{\sigma_{y s} \text { pre }- \text { strain }}\right)^{\alpha}
$$

Figure 11 shows examples of experimental results on the toughness deterioration due to the cold working. The material tested is a $500 \mathrm{MPa}$ class high strength steel and the pre-strain in terms of equivalent strain was given by cold rolling. Pre increase in the yield strength by the prestrain can be estimated from the constitutive equation of the virgin material. Two solid lines in the figure show predicted value of the toughness from experimental results on toughness and mechanical properties of the virgin material. Equation (8) indicates that the deterioration in toughness due to the pre-straining is strongly dependent on the strain hardening of materials and the exponent $\alpha$ which is related to the statistical distribution of micro-crack nuclei. An ex- 


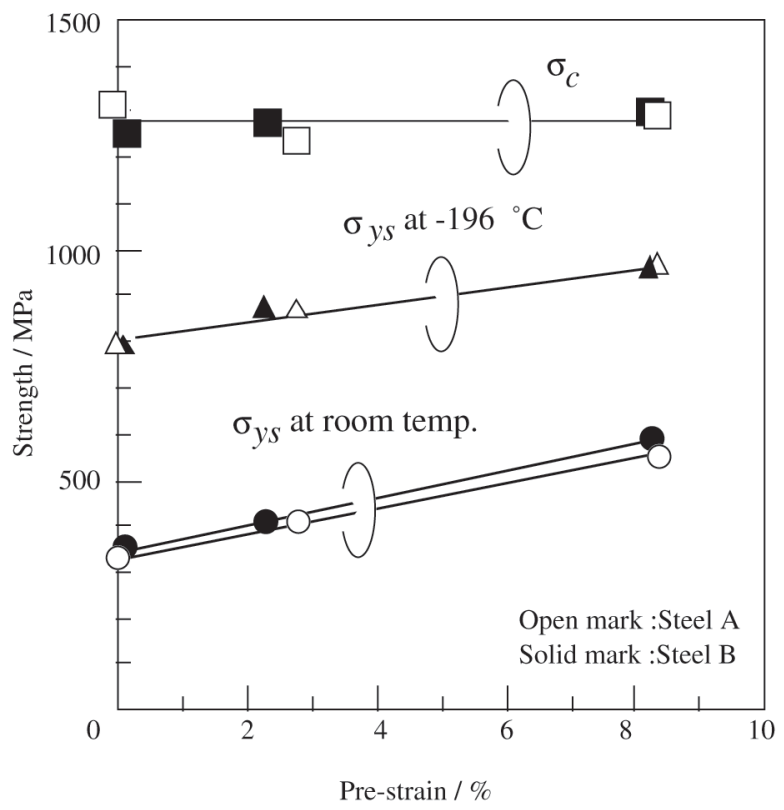

Figure 10. Tensile properties of steels tested as a function of the pre-strain ${ }^{22}$.

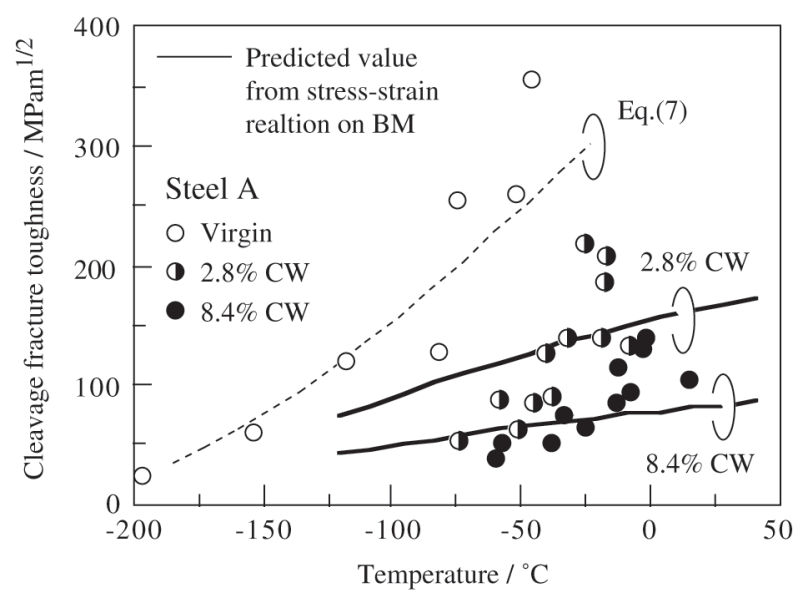

Figure 11. Deterioration of fracture toughness due to cold working.

perimental result that the yield ratio of materials has significant influence on toughness deterioration has been shown elsewhere ${ }^{22}$.

\section{Deterioration of the toughness due to irradiation}

Analogy in deterioration of the toughness due to the prestraining is applicable to the irradiation embrittlement. The neutron irradiation causes increase of the yield strength of steels. Figure 12 shows an experimental result on the dete-

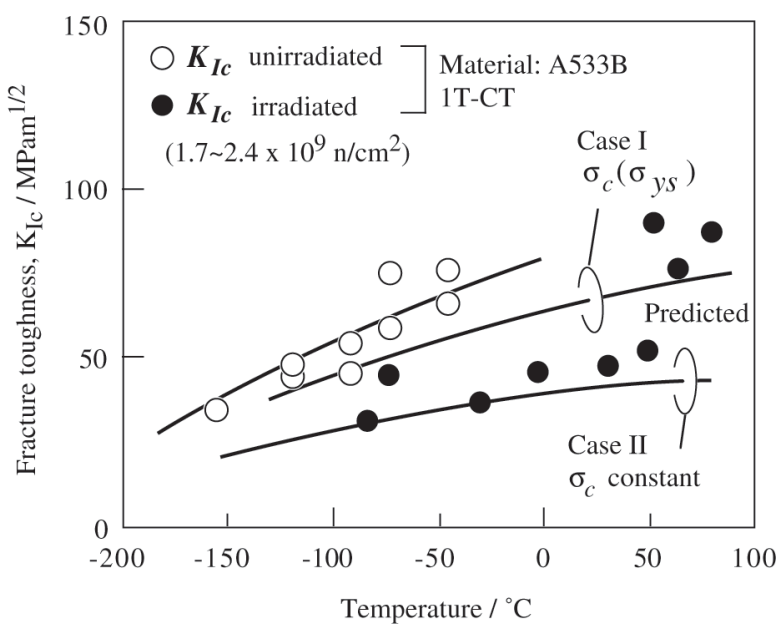

Figure 12. Irradiation effect on fracture toughness of a low alloy steel $^{28}$.

rioration due to the irradiation ${ }^{28}$ and its prediction according to Eq. (7). Since it can be assumed that metallurgical factors such as micro-structure and carbide size/distribution are not varied with the irradiation, the exponent $\alpha$ in Eq. (7) is considered kept constant. With two assumptions for the cleavage fracture stress the deterioration in toughness can be predicted as shown in Fig. 12 from the experimental results on hardening due to the irradiation. The cleavage fracture stress was assumed to be proportional to the increase of the yield strength (Case I) or to be constant (Case II).

\section{Improvement of the toughness with the increase of $\mathrm{Ni}$ contents}

It is well known that nickel is one of the most effective alloy elements to improve the fracture toughness of low carbon steels. On the other hand, the detrimental effect of $\mathrm{Ni}$ is also observed depending on cooling rate at the tempering. There are many mechanisms to explain the toughness improvement owing to the nickel addition. One of rational mechanisms is that the nickel addition restrains the increase of the yield strength at low temperature range ${ }^{29}$. It seems to be rational in accordance with Eqs. (3) and (7), while the deterioration can not be explained. Experimental results on both improvement and deterioration in toughness ${ }^{30}$ shall be introduced in the present paper.

The chemical compositions of materials tested and thermal cycles of heat treatments, are shown in Table 1 and Fig. 13, respectively. Thermal cycles were selected to keep the micro-structure be the same as upper bainite for the materials with different $\mathrm{Ni}$ contents. The same thermal cycle was 
Table 1. Chemical compositions of steels tested for investigation of the effect of Ni contents (mass\%).

\begin{tabular}{|c|c|c|c|c|c|c|c|c|c|}
\hline & $\mathrm{C}$ & $\mathrm{Si}$ & $\mathrm{Mn}$ & $\mathrm{P}$ & $\mathrm{S}$ & $\mathrm{Al}$ & $\mathrm{N}$ & $\mathrm{Ti}$ & $\mathrm{Ni}$ \\
\hline $0 \% \mathrm{Ni}$ & 0.074 & 0.22 & 0.77 & 0.005 & 0.003 & 0.028 & 0.004 & 0.009 & - \\
\hline $2 \% \mathrm{Ni}$ & 0.074 & 0.22 & 0.76 & 0.005 & 0.004 & 0.030 & 0.002 & 0.009 & 1.97 \\
\hline $4 \% \mathrm{Ni}$ & 0.068 & 0.22 & 0.78 & 0.005 & 0.004 & 0.027 & 0.003 & 0.009 & 4.01 \\
\hline
\end{tabular}

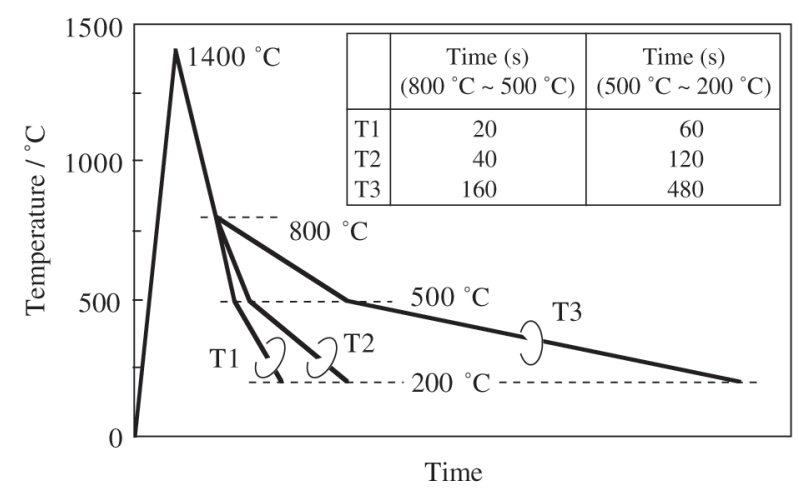

Figure 13. Thermal cycles subjected to steels tested.

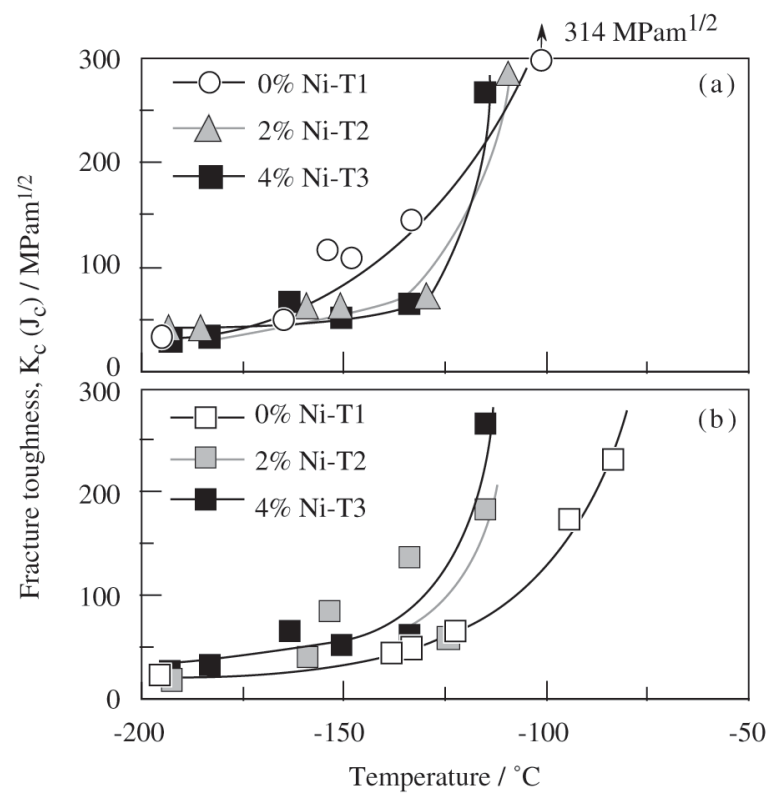

Figure 14. Temperature dependence of fracture toughness for the steels tested. (a) Steels with the same microstructure; (b) Steels subjected to the same heat treatment.

simultaneously applied regardless of different Ni contents, that caused different micro-structure.

Fracture toughness testing and notched round bar tensile test were performed for each steels. The results on the fracture toughness test are shown in Fig. 14. The toughness values are converted from $\mathrm{J}_{\mathrm{c}}$ values evaluated in the test to

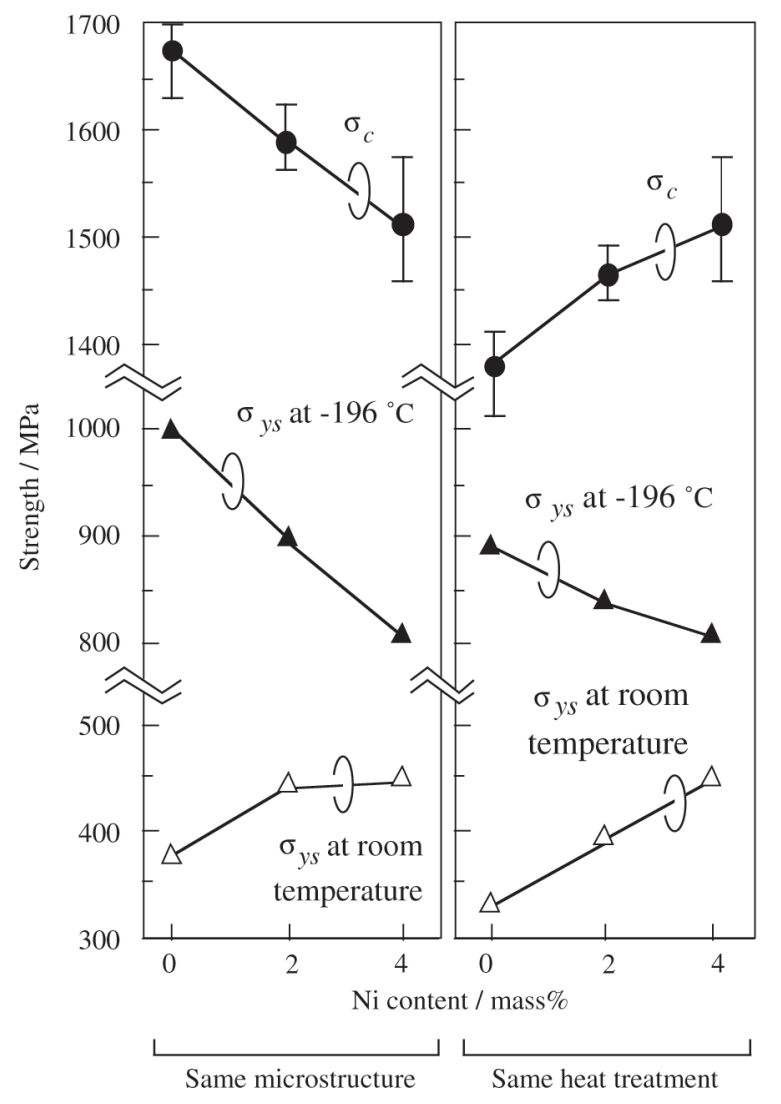

Figure 15. Effect of Ni contents on yield strength and cleavage fracture strength of the steels tested.

equivalent $\mathrm{K}_{\mathrm{c}}$ values. In case that the micro-structure is the same, $\mathrm{Ni}$ addition leads to inferior toughness, while in case of the same thermal cycle improvement of the toughness is achieved. This apparent discrepancy is caused from opposite effect of $\mathrm{Ni}$ on the cleavage fracture stress. Figure 15 shows the effect of Ni contents on the yield strength and the cleavage fracture stress, $\sigma_{c}$ obtained in the round bar tensile specimens. The effect of $\mathrm{Ni}$ contents on $\sigma_{c}$ is contrary depending on the micro-structure and consistent with the toughness variation. Although discussion on detail from the metallurgical point of view is not objectives of the present work, the cleavage fracture stress is governed by the size of 


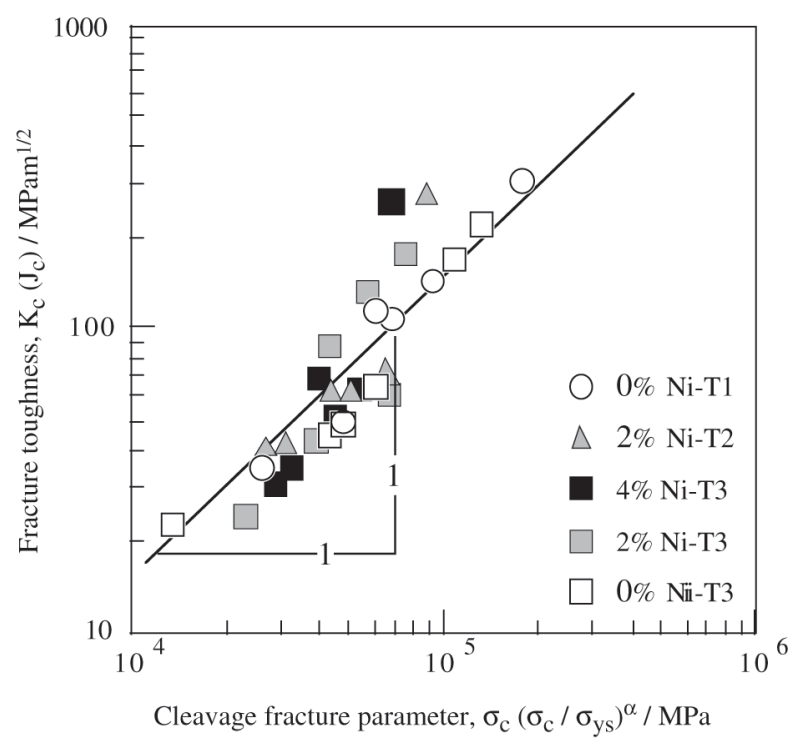

Figure 16. Correlation between fracture toughness and cleavage fracture parameter.

second phase hard particles and flow properties of the matrix (dislocation mean free path) ${ }^{30}$. Correlation between the toughness and the cleavage fracture parameter in accordance with Eq. (7) was investigated as shown in Fig. 16. The results indicates that both the improvement and the deterioration in toughness due to the addition of $\mathrm{Ni}$ can be comprehensively explained through the formulation of the toughness.

\section{Conclusions}

Formulation of the cleavage fracture toughness of steels was examined on the basis of the statistical local fracture criterion. The Weibull stress criterion model proposed by Beremin Group derives a description of the toughness in terms of fracture and mechanical properties of materials. Experimental results in notched round bar specimens demonstrate that the critical Weibull stress for the cleavage fracture can be represented with the deterministic critical fracture stress defined as the maximum tensile stress at the cleavage fracture. Based on this result correlation between the cleavage toughness and the critical fracture stress was investigated for more than 50 types of steels in accordance with the analogy of the statistical Beremin model.

Experimental results were well consistent with the theoretical prediction. Simultaneously, experimental results on the scatter of the toughness and on the specimen thickness effect on the toughness confirmed the validity of the model. The description of the toughness could show us comprehensive understanding on the elements which compose the cleavage toughness. Deterioration of the toughness due to pre-straining and irradiation were well explained with the increase of the yield strength. The toughness is in inverse proportion to the $\alpha$ th power of the yield strength. Temperature and strain rate dependence of the toughness may be also explained with the variation of the yield strength of the materials.

Representatively the effect of the Ni contents on the cleavage toughness was investigated through the formulation of the toughness. It was clarified that the improvement and deterioration both are possible depending on the effect of the Ni on the cleavage fracture stress in spite of the decrease in the yield strength at low temperature region.

It should be conclusively noticed that the effect of these mechanical and metallurgical factors on the toughness is presumed to be differently dependent on materials except for the thickness effect, since the value of $\alpha$ might be governed by the statistical nature of the micro-crack nuclei.

\section{References}

1. MacMahon, C.J.; Cohen, M. Acta Metall., v. 13, p. 591, 1965.

2. Smith, E. Proc. Conf. Physical Basis of Yield and Fracture, Physical Soc. of Oxford, p. 36, 1966.

3. Knott, J.F. J. Iron and Steel Inst., 204, p. 104, 1966.

4. Hahn, G.T. Met. Trans., A15, p. 947, 1984.

5. Knott, J.F. Fracture '77, Proc. $4^{\text {th }}$ ICF, v.1, p. 61, 1977.

6. Curry, D.A.; Knott, J.F. Metal Sci., v. 13, p. 341, 1979.

7. Petch, N.J.; Armstrong, R.W. Acta Metall., v. 34, p. 1121, 1986.

8. Aihara, S.; Haze, T. TMS Annual Meeting, Phoenix, AZ, Jan.25-28, paper No. A88-14, 1988.

9. Beremin, F.M. Met. Trans., A14, p. 2277, 1983.

10. Mudry, F. Nuclear Eng. and Design, v. 105, p. 65, 1986.

11. Ritchie, R.O.; Knott, J.F.; Rice, J.R. J. Mech. Physics of Solids, 21, p. 395, 1973.

12. O'Dowd, N.P.; Sih, C.F. J. Mech. Physics of Solids, v. 40, p. 939, 1992.

13. Anderson, T.L.; Dodds, R.H. J. Testing and Evaluation, v. 19, p.123, 1991.

14. Wallin, K. Eng. Fracture Mechanics, v. 19, p. 1085, 1984.

15. Ruggieri, C.; Minami, F.; Toyoda, M.; Hagiwara, Y.; Inoue, T. J. Soc. Naval Architects of Japan, n. 171, p.493, 1992.

16. Miyata, T.; Tagawa, T.; Yang, H. J. Testing and Evaluation, v. 28, p. 62, 2000.

17. Pineau, A. Advances in Fracture Research, Proc. of ICF5, v. 2, p. $553,1981$.

18. Knott, J.F. Fundamentals of Fracture Mechanics, Butterworth, London, p. 180, P201, 1973.

19. Bowen, P.; Knott, J.F. Metal Sci., 16, p. 225, 1984.

20. Parks, D.M. J. Eng. Mat. Techn., 98, p.90, 1976. 
21. Curry, D.A. Metal Sci., 16, p. 435, 1982.

22. Miyata, T.; Tagawa, T. J. de Physique IV, Colloque C6, v. 6, p. 235, 1996.

23. Hahn, G.T.; Hoagland, R.G.; Rosenfield, A.R. Metallurgical Trans., v. 2, p. 537, 1971.

24. Japanese Soc. for Promotion of Sci., Committee 129, Report on Round Robin Test on the Fracture Toughness in Transition Temperature Region, 1985.

25. Miyata, T.; Otsuka, A.; Katayama, T.; Otake, T. Defect Assessment in Components - Fundamentals and Appli- cation, ESIS/EGF9(edited by Blauel, J.G., and Scwalbe, K.H.), Mechanical Engineering Publication, p. 501, 1991. 26. Terasawa, K.; Ohtani, M.; Yoshida, T.; Terai, K. J. Soc. Naval Arch. Japan, 109, p. 317, 1961.

27. Groom, J.D.G.; Knott, J.F. Metal Sci., 19, p. 390, 1975.

28. Hunter, C.W.; Williams, J.A. Nuclear Eng. and Design, 17, p.131, 1971.

29. Jolley, W. Trans. AIME, 242, p. 306, 1968.

30. Tagawa, T.; Aihara, S.; Miyata, T. Tetsu to Hagane, v. 82, p. 859, 1996 (in Japanese). 